\title{
Resenha: The Model As Performance: Staging space in theatre and architecture
}

\author{
Niuxa Dias Drago \\ Universidade Federal do Rio de Janeiro - UFRJ, Rio de Janeiro/RJ, Brasil \\ Email: niuxadrago@gmail.com
}

\section{Resumo}

O livro trata do modelo em escala, tanto na arquitetura como na cenografia, e suas potencialidades performáticas. Os autores estabelecem uma distinção entre modelo ilustrativo, modelo iterativo e modelo autônomo, e dedicam sua análise a este último. Além de uma revisão histórica de modelos paradigmáticos para os campos em análise, enxergam nas tendências atuais da Bienal de Veneza e da Quadrienal de Praga uma valorização dos conceitos espaciais através do uso do modelo autônomo.

\section{Palavras-chave}

Campo Ampliado. Modelo Cenográfico.

Modelo Arquitetônico.
The book deals with the scale model and its performance potentialities, both in architecture and scenography. The authors distinguish between illustrative model, iterative model and autonomous model, devoting their analysis to the latter one. In addition to a historical review of paradigmatic models in the fields under analysis, they see in Venice Biennial and Prague Quadrennial current trends a valorization of spatial concepts through the use of the autonomous model.

\section{Keywords}

Extended Field. Scenographic Model.

Architectural Model. 


\section{Resenha}

Lançado em 2018, The Model as Performance é o $3^{\circ}$ volume da série Performance + Design, editada por Di Benedetto, McKinney e Palmer, que já contava com Scenography Expanded (MCKINNEY e PALMER, 2018) e The History and Theory of Environmental Scenography (ARONSON, 2018, $2^{\mathrm{a}}$ ed.). Diferente dos anteriores, The Model As Performance dedica-se a um objeto-tema: o modelo em escala, arquitetônico ou cenográfico. São abordados modelos de diferentes momentos históricos, desde o Renascimento, considerados elementos-chave para o avanço do conhecimento técnico ou conceitual sobre o espaço. Os autores, Thea Brejzek e Lawrence Wallen, são professores da Universidade Técnica de Sidney e atuam no ensino de design, definindo de maneira muito ampla o modelo, seja em escala, aspecto ou conceito. O livro está entre as dez mais relevantes publicações dos últimos anos, segundo o júri da Quadrienal de Praga 2019. Sua seleção coroa o cuidadoso trabalho dos autores - que montaram e fotografaram modelos originais de Gordon Craig guardados na Biblioteca Nacional da França - e o interesse crescente no campo ampliado da arquitetura e da cenografia.

A hipótese apresentada é de que os modelos nem sempre são representativos de edificações existentes ou demonstrativos de projetos. A esses modelos, os autores chamam representacionais ou ilustrativos, designando-os por vezes com o termo mockup. ${ }^{1}$ Outros modelos servem como instrumento de trabalho para arquitetos e cenógrafos realizarem testes e ajustes. A esses, os autores chamam iterativos. Embora admitam que nem sempre

\footnotetext{
1 Os autores não sentem necessidade de ratificar a diferença entre model e mockup, já estabelecida no vocabulário inglês (em português mockup costuma ser traduzido por "maquete"). Aplicam quase sempre o termo model, utilizando mockup apenas para representações de edifícios já existentes e reconhecidos, ou representações ilustrativas de cor, material ou situações ambientais de projeto, que podem adquirir a escala 1:1. O termo model, bastante mais abrangente, é sempre preferido para designar os objetos analisados.
}

é possível separar tão claramente os modelos segundo seu objetivo, a tese principal é de que o modelo pode ser, ele mesmo, uma criação espacial autônoma, uma 'cosmopoiesis' ou criação-de-mundo (world making). Nas 154 páginas, os autores se dedicam, então, a demonstrar, através de uma seleção cronológica de exemplares, tanto de modelos de edificações quanto de dispositivos cênicos, e muitas vezes coadunando ambos, que o modelo autônomo é "inerentemente performativo e epistêmico".

O primeiro capítulo apresenta uma revisão bibliográfica sobre o objeto. Visita obras que se debruçam sobre diferentes tipos de modelo em escala e sobre o sentido filosófico do modelo platônico que, sendo ele mesmo "produtor de realidade", segundo os autores, se aproxima do conceito de "modelo autônomo". Os autores apresentam, também, três pioneiras exposições de cenografia no século XX: Zurich (1914), Amsterdan (1922) e Nova York (1934). Tais exposições mostram a transformação do espaço cênico após Craig e Appia - que se encontraram apenas em Zurich, por ocasião desta Theaterkunst Exhibition - e a importância dos modelos como forma de criar com o movimento sob a luz.

$\mathrm{Na}$ análise cronológica que se segue, os autores aprofundam a reflexão sobre exemplos já conhecidos, mas, por isso mesmo, facilmente recuperáveis dentro da nova hipótese. Do capítulo 2 ao 5 , entre arquitetura e cenografia, abordam desde o Teatro de Sabionetta, de Scamozzi - alegoria do poder do duque que integra, numa mesma organização perspéctica, a cidade, o edifício teatral e o cenário - até os dispositivos cênicos criados por Albert Speer para representar a nova ordem social do Terceiro Reich. Os autores passeiam do Teatro da Memória de Giulio Camillo, entendido, junto com os studiolli e gabinetes de curiosidades, como representações do conceito de Teatrum Mundi, onde se ensaiava novas formas de conhecimento na Idade Moderna, até o Futurama da Exposição Internacional de Nova York de 1939 , onde os norte-americanos ensaiavam o futuro para após a guerra iminente. Dos Teatri del Mondo 
venezianos, imagens acabadas do sentimento barroco, relidas por Aldo Rossi para a Bienal de 1980, aos espetáculos ópticos de Servandoni e Loutherbourg que, para além de entreter, contribuem para transformar técnica e conceitualmente a cenografia, sendo, portanto, importantes modelos autônomos.

O livro corrobora o entendimento da arquitetura e do dispositivo cênico como performáticos per se, e de cenógrafos e arquitetos como, antes de tudo, pesquisadores do espaço. O último capítulo reforça esse aspecto ao analisar o uso de modelos 1:1 nas últimas edições tanto da Quadrienal de Praga como da Bienal de Veneza.

Os autores tangenciam várias vezes os temas do modelo digital e da realidade aumentada, abordados amplamente nas discussões da Quadrienal 2019. Para tratá-los, prometem um futuro volume. Esperamos que seja tão instigante quanto este.

\section{Referência}

BREJZEK, Thea; WALLEN, Lawrence. The Model as Performance - staging space in theatre and architecture. $1^{\mathrm{a}}$ ed. London: Bloomsbury Methuen Drama, 2018. $188 \mathrm{p}$.

Recebido:29/08/2019

Aprovado: 26/02/2020 